"Las Funta, Col., Fuly 29.

"Good observations of the eclipse at Las junta. Complete set of photographs.

"ASAPH HALL"

"Creton, W.T., July 29

"Sky cloudless and observations perfectly successful. Six photographs of corona. Four polariscope photographs of corona and a fine drawing obtained. No ultra violet spectrum visible during totality.

"W. HARKNESS"

"Central City, Col., July 29

"Whole eclipse perfectly observed. I find no Vulcan as large as sixth magnitude. Hastings finds consistent tangential polarisation. Drawings and photographs of corona. Diffraction shade bands observed.

"E. J. HOLDEN"

"Separation, W.T., July 29

"Observations here very successful. Saw wings of light, supposed to be zodiacal light, extending $6^{\circ}$ on each side of the moon in the direction of the ecliptic. Commander Sampson, U.S.N., found no dark lines in continuous spectrum of corona. Line 1,474 seen near sun's limb. No bright lines visible a few seconds after totality.

\section{"S. NEWCOMB"}

"Pike's Peak, Col., July 29

"Fair weather after a week's storm. Observations successful in a marvellously clear sky. Corona resembling zodiacal light followed in one direction twelve diameters from the sun.

"S. P. LANGLEY"

"Eclipse successfully observed at Dallas, Texas. All four contacts satisfactory. No inter-Mercurial planet seen with comet-seeker. Thin clouds. No stars seen near the sum. Corona very brilliant. Several drawings secured and photographs taken.

"D. P. TODD"

It is telegraphed to the Tribune from-

"Havana, July 30.-Yesterday the total eclipse of the sun was visible in this latitude. The sky was perfectly clear, and complete observations were made. A report of the results obtained was expected to-day, but the scientific commission which took observations at Mariel, where the meridian passes, has not returned yet."

"Quebec, July 30.-The eclipse of the sun yesterday, was witnessed under the most favourable circumstances."

"Washington, July 30.-The Signal Service Observer at Virginia City, Mont., reports to the Chief Signal Officer as follows:--'Our four telescopic stations have got all the contacts nicely, and three sketches of the corona."

\section{OUR ASTRONOMICAL COLUMN}

The SAturnian SATEllite Hyperion.--The following ephemeris of Hyperion is deduced from the elements which were calculated by Prof. Asaph Hall, upon his observations in 1875 with the Washington 26-inch refractor.

\begin{tabular}{|c|c|c|c|c|c|c|c|c|c|c|c|}
\hline & & & $\mathrm{AT}$ & $\mathrm{GR}$ & REENWIC & I MID & $\mathrm{NI}$ & $\mathrm{HT}$ & & & \\
\hline & & & Position. & & Distance. & & & & Position & & Distance. \\
\hline Aug. & 24 & $\ldots$ & $2 \dot{68}$ & $\ldots$ & 147 & Sept. & & $\cdots$ & 89 & $\cdots$ & I $2 \ddot{5}$ \\
\hline ", & 25 & $\cdots$ & 263 & $\cdots$ & 93 & " & 5 & $\cdots$ & 82 & ... & 53 \\
\hline ," & 26 & ... & 243 & ... & 37 & , & 6 & $\cdots$ & 301 & ... & 30 \\
\hline , , & 27 & ... & 125 & ... & 36 & , & 7 & $\ldots$ & $28 I$ & ... & 99 \\
\hline ,", & 28 & $\cdots$ & 105 & ... & 93 & , & 8 & $\ldots$ & 277 & $\cdots$ & 167 \\
\hline ," & 29 & $\cdots$ & 100 & $\cdots$ & 146 & , & 9 & $\cdots$ & 276 & $\ldots$ & 213 \\
\hline ," & 30 & $\cdots$ & 97 & ... & 189 & , & ro & $\ldots$ & 274 & $\ldots$ & 239 \\
\hline Sept. & $3^{I}$ & $\cdots$ & 96 & $\ldots$ & 218 & , & $I I$ & $\ldots$ & 273 & $\ldots$ & 244 \\
\hline & I & $\ldots$ & 94. & $\cdots$ & 228 & , & 12 & ... & 272 & $\ldots$ & $23 I$ \\
\hline ," & 2 & $\cdots$ & 93 & $\cdots$ & 216 & ," & $x_{3}$ & $\cdots$ & 271 & $\cdots$ & 201 \\
\hline , & 3 & $\cdots$ & 92 & $\cdots$ & I 81 & , & 14 & $\cdots$ & 209 & $\cdots$ & 158 \\
\hline
\end{tabular}

The plane of the orbit of the satellite is assumed to coincide with that of the ring, and as the earth has passed through the plane since the period included by the ephemerides which appeared in this column last year, the apparent motion of the satellite is now reversed, or the angles of position diminish. The above ephemeris includes an entire revolution of the satellite, and will serve, if necessary, to afford an idea of its position at any time during the present opposition, remarking that the satellite will be at its peri-saturnium at the following times: August 15.0939, September 5.4052, September $26^{\circ} \mathrm{I}_{5}$, October 18.0278 , and November 8.3391.

OLBERS' STAR NEAR $\gamma$ PEGasi, - On September 27, r820, Olbers remarked a star of $6.7 \mathrm{~m}$. not entered upon Harding's map, and which Harding had not seen during two comparisons of it with the heavens. It was somewhat brighter than 39 and nearly equal to 40 Piscium. Olbers accounted for it not having been observed on the meridian by the fact of its culminating within a few seconds of $\gamma$ Pegasi. He watched it during the remainder of the season without noticing any change in brightness, and it was from the circumstance of his attention being thus directed to this quarter of the sky that he made an independent discovery of the comet of 1821. The star is in the Durchmusterung as $7.5 \mathrm{~m}$., and was observed once by Argelander (October 24, 1861) the resulting position for $1855^{\circ}$ being R.A. oh. $5 \mathrm{~m}$. $4 \mathrm{I} \cdot 8 \mathrm{~s}$., N.P.D. $73^{\circ} 52^{\prime} 56^{\prime \prime}$. Bessel did not observe it, but it is suspicious that he has a star $9 \mathrm{~m}$. only, preceding Argelander's position of Olbers' star $7^{\circ}$ Os. and $3^{\prime} 58^{\prime \prime}$ to the north, where the Durchmusterung has no star. It is a case for some one of those observers who are occupied with the variable stars to explain.

\section{LETTERS TO THE EDITOR}

[The Editor does not hold himself responsible for opinions expressed by his correspondents. Neither can he undertake to return, or to correspond with the writers of, rejected mamuscripts. No notice is taken of anonymous communications.

TThe Editor urgently requests correspondents to keep their letters as short as possible. The pressure on his space is so great that it is impossible otherwise to ensure the appearance even of com. munications containing interesting and novel facts.]

\section{A New Mineral}

Mr. BARneTr, of Chyandour, near Penzance, sent to the British Museum some time ago a mineral which appears to be new.

It is white with a slight tint of blue or greenish blue, and occurs as a layer sometimes of a quarter of an inch thickness, generally of a uniform fibrous structure, lining hollows or encasing quartz and other minerals. It is associated with earthy chlorite and quartz; iron pyrites, some copper pyrites, and mispickel being disseminated in the lode-material. Scorodite in bosslike aggregations also occurs with it, and in at least one instance the interior of the bosses of scorodite is filled with the mineral in question.

Dr. Flight has analysed it, and, though the mode in which the water is present has to be established more certainly, the general result of the analysis may be stated to be the assigning to the mineral a formula expressed, in "old style," as

$$
3 \mathrm{R}_{2} \mathrm{O}_{3}, \mathrm{As}_{2} \mathrm{O}_{5}+16 \mathrm{H}_{2} \mathrm{O} \text {, }
$$

$\mathrm{R}_{2} \mathrm{O}_{3}$ representing alumina with a notable amount of ferric oxide. The tint seems due to about one per cent. of copper, and a small amount of a sulphate is also present. The presence of the sulphate and general character of the composition would lead one to place the mineral with Pitticite, or "iron-sinter." But the formula, as Dr. Flight has pointed out, is so nearly that of an arsenical (instead of a phosphatic) Evansite that the true place of the mineral seems to be near the Evansite of David Forbes. I propose to call it Liskeardite, and to describe it more precisely hereafter.

British Museum, Mineral Department, August 12

\section{The Colouring of Birds' Eggs}

WITHIN the last few months several notices have appeared in both England and Germany of supposed newly-discovered 